\title{
PETROGRAPHY AND DIAGENETIC HISTORY OF NAGRI FORMATION SANDSTONE IN DISTRICT BAGH AND MUZAFFARABAD, PAKISTAN
}

\author{
Noman Abbasi*, Muhammad Yasin \\ Institute of Geology, University of Azad Jammu and Kashmir, Muzaffarabad, Pakistan \\ *Corresponding Author: nomanabbasi51@gmail.com
}

This is an open access article distributed under the Creative Commons Attribution License, which permits unrestricted use, distribution, and reproduction in any medium, provided the original work is properly cited

\section{ARTICLE DETAILS}

\section{Article history:}

Received 12 May 2017

Accepted 12 July 2017

Available online 17 October 2017

\section{Keywords:}

lithic graywackes, geological significances, tectonic upliftment, diagenetic

\begin{abstract}
The petrographic analysis of Nagri Formation sandstone based on outcrop study and interpretation of thin sections with special emphasis on the diagenetic history from widely separated areas was accomplished. The calcite concreations, hematite leaching, petrified wood fossils, spheroid weathering, quartz filled joints and the meso scale drag folding has few geological significances. Interpretation of thin sections revealed that the sandstone is lithic arenite and lithic graywackes. The concavo-convex, sutured contacts and muscovite deformations indicates that the compaction of sand under lithostatic stress during early diagenesis. The pore water has widened the intergranular distance in some rocks by dissolving the fractured surfaces of carbonates and other grains, enhancing the concentration of carbonates in water at high $\mathrm{pH}$. On the other hand, the silica dust formation can be attributed to the abrasion of quartz grains during compaction, alteration of feldspar to sericite and overgrowth on quartz by calcite under low $\mathrm{pH}$ of solution and pressure solution. The leaching and precipitation of hematite along fractures and thin coating around the grains indicates iron oxides paragenesis from chlorite and biotite in the area. The clay mineral authigenesis includes replacement along the cleaved and fractured feldspar and sericitation. Further elaborations indicate plastic deformations of hydrolytically weak quartz grains and deformations by tectonic upliftment, enhancing the permeability and reservoir quality of sandstone.
\end{abstract}

\section{INTRODUCTION}

The study area near Sudan Gali and Chikar (Figure 1), District Bagh and Muzaffarabad, Azad Jammu and Kashmir forms the Northern mountaineous belt of Pakistan. The area includes high peaks, defile mountaineous passes, dense forests, pastures and meadows. The area is exposed to cold winds during winter snow. The fabulous valleys are drained by perennial streams normally inundated during summer monsoon rain. The bed rock in the streams (parallel with some rectangular bends in) course is concealed beneath the wide distribution of sandstone, gravels and sand deposits. These streams upon harnessing may form small dams and the water may be used for power generation, agriculture and other house hold purposes [1]. Anyhow, the rock sequence forms best exposures of the Murree and Nagri Formations in the region. The Nagri Formation sandstone is the name assigned to rocks of Miocene epoch having continental origin [2]. The sandstone, commonly lithic arenite and lithic graywacke in composition is greenish grey, medium to coarse grained, salt and pepper textured, cross bedded, massive and fluviatile in origin with best exposures accessed along road side and drainage during the research [3]. In places, the sandstone bears calcite concreations (Figure 2A), hematite leaching (Figure 2B), petrified wood fossils (Figure 2C), spheroid weathering (Figure 2D), quartz filled joint (Figure 2E) and calcite cement. The meso scale drag folding in the incompetent strata has been observed.

The fractured sandstone in the area are best aquifers that yield water suitable for drinking and another household uses.

However, the aim of research is to interpret the diagenetic history of the rocks based on outcrop study and the petrographic analysis of minerals, matrix and cement within sandstone rock.
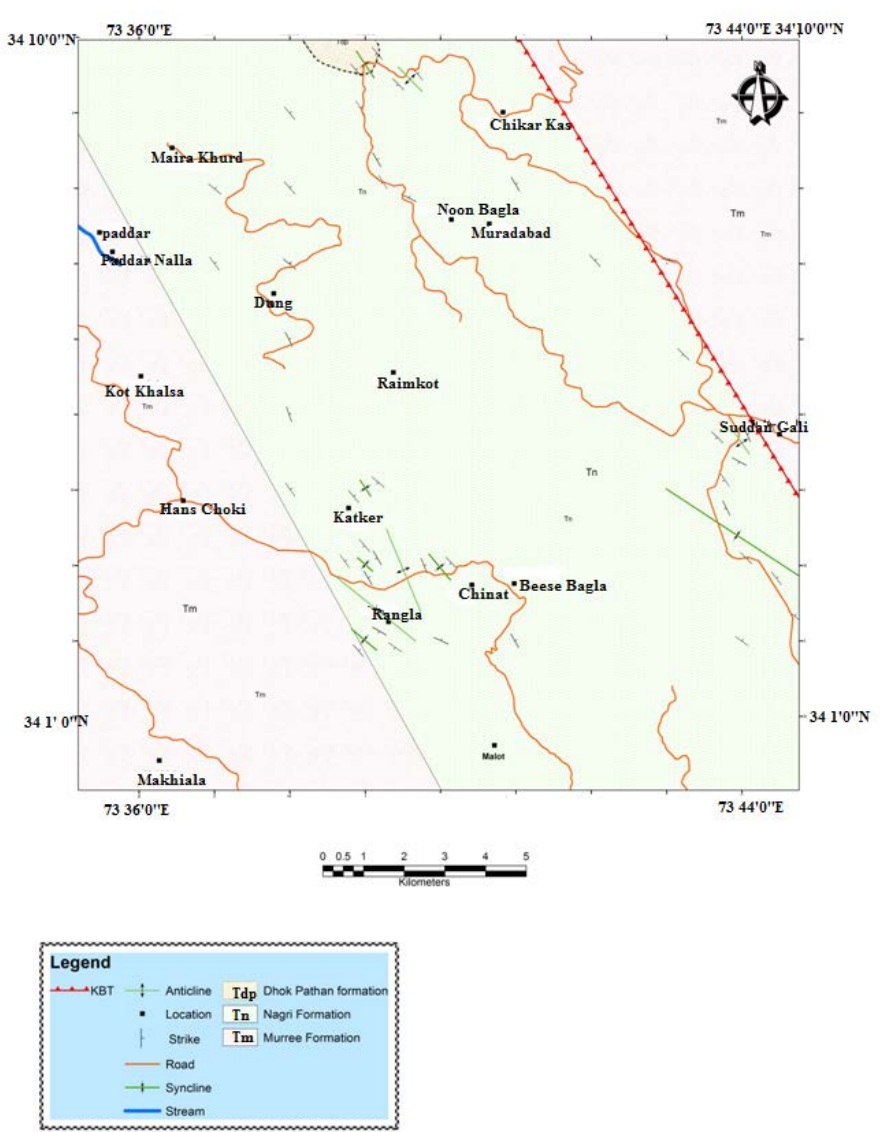

Figure 1: Geological map of the study area. The study area in the District Bagh and Muzaffarabad, Azad Jammu and Kashmir, Pakistan forms the Northern mountaineous belt of Pakistan.

\section{PREVIOUS WORK}

This is the first comprehensive petrographic study of the area with the special emphasis on the diagenetic history of the rock. 


\section{MATERIAL AND METHOD}

The research work includes geological mapping and outcrop study within 90 days field work. Only a few features having geological significances were captured in a digital camera. The thin sections of selected rock samples were prepared and the mineral contents, texture, matrix and cement were identified and interpreted under microscope. The photomicrographs were taken for further elaboration.
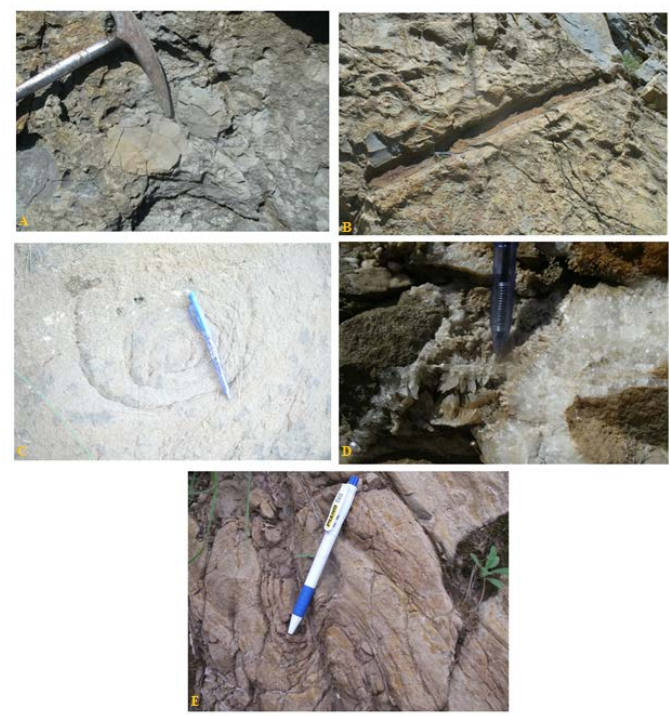

Figure 2: Field photographs showing (A) calcite concretion in sandstone of Nagri Formation (Noon Bagla), (B) hematite leaching along the petrified wood fossil in Nagri Formation (Chikar), (C) spheroidal weathering in Nagri Formation Sandstone (Chikar), (D) Quartz filled Joint in the Nagri Formation, (E) Meso scale Drag Folding in a bed of Nagri Formation.

\section{RESULTS AND DISCUSSIONS}

The compaction and pressure solution, carbonate, silica and hematite cementation, clay minerals authigenesis and late diagenetic deformations were encountered during the research.

\subsubsection{Compaction and Pressure Solution}

During early stages of diagenesis, compaction of sand grains involves dewatering and closer packing. Further compaction resulted through increase in overburden or lithostatic pressure. The lithostatic pressure caused fracturing of brittle grains and bending of weak grains [4]. The concavo-convex (Figure 3A), sutured contacts (Figure 3B) and deformed muscovite indicated that sand was compacted due to lithostatic pressure during early diagenesis. The lithostatic pressure and water mineral interaction caused the biotite and feldspar to alter into secondary minerals in some rocks. The limestone clasts also exhibited stylolites (Figure 3C) probably developed during diagenesis [5]. The pressure solution in quartz is also increases at high temperature [6].

\subsubsection{Carbonate Cementation}

The carbonate (Figure 3C). is the early diagenetic and high content of cement in the rocks. The carbonates acted as the main cementing material in Nagri sandstone. The calcium rich pore water initiated process of cementation of sand. Other source of initial carbonate cement is that of adhesion and fracturing of limestone clasts due to lithostatic pressure. The pore water dissolved fractured surfaces of carbonates and other grains in the sand enhancing the concentration of carbonates in water. The carbonates are precipitated in pores and inter-granular spaces. The carbonates precipitation also increased the displacement of grains framework by widening the intergranular distance in some rocks.

The increase of overburden pressure resulted in decrease of volume and caused the dissolution of carbonate clasts, quartz grain boundaries and alteration of feldspar. The pore water fractured the grains in response to increasing overburden pressure. The carbonates precipitated in fractures and forced the particles to split as observed in quartz and clasts. These fractures have increased the secondary porosity of the rock to conduct fluids through them. The overgrowth of quartz by carbonates is also observed in the rocks (Figure 3D). The quartz grains cemented by carbonates are irregular in shape due to etching at margins. The precipitation of carbonates and their overgrowth around quartz indicate that $\mathrm{pH}$ of pore water in sandstone was higher.
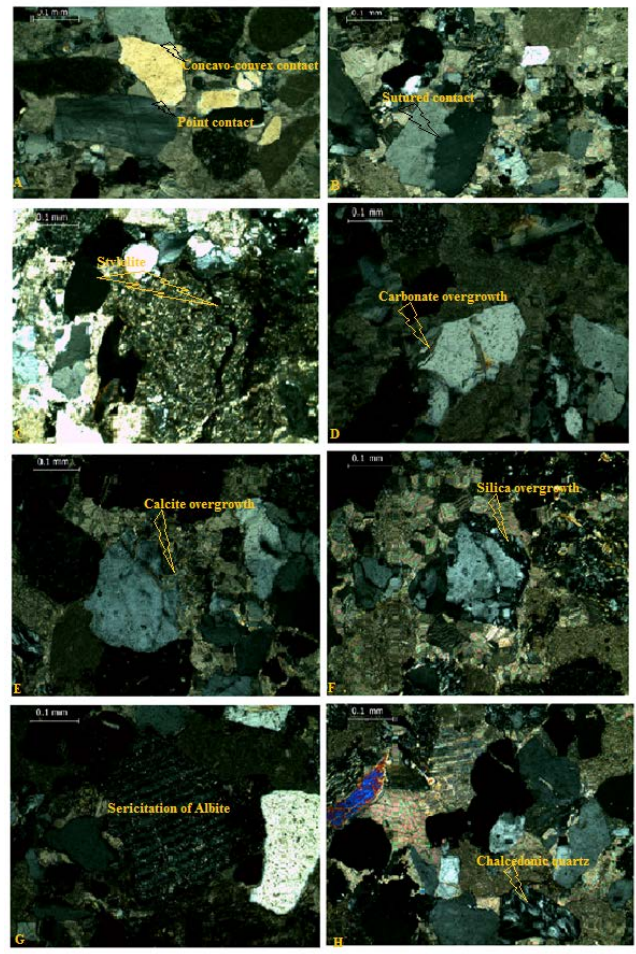

Figure 3: Photomicrographs showing (A) concavo-convex and point contact between quartz grains (CN; 10X), (B) pressure solution forming suture contact within quartz (CN; 10X), (C) stylolite in calcite cement (CN; 10X), (D) carbonates overgrowth on quartz (CN; 10x), (E) replacement of quartz by calcite (CN; 10x), (F) silica over growth on quartz (CN; 10x), (G) albite transformation to sericite $(\mathrm{CN} ; 10 \mathrm{x}),(\mathrm{H})$ fabric texture of chalcedonic quartz overgrowth (CN; 10x).

\subsubsection{Silica Cementation}

The quartz overgrowth (Figure 3F), carbonates overgrowth by silica (Figure $3 \mathrm{E}$ ) and precipitation of silica (Figure $3 \mathrm{H}$ ) in the fracture of fragments has been observed in some rocks. The silica cement was precipitated around the quartz grains.

The origin of silica for quartz overgrowth may be attributed to pressure solutions. The overburden pressure caused fracturing of quartz and dissolution of its margins. The silica is released in the pore waters and reprecipitated as overgrowth on quartz. The silica in solutions may also come from more distant sites of pressure solutions or from the source region. The other possible sources may be the silica dust produced by abrasion of quartz grains during compaction, alteration of feldspar to sericite (Figure 3G) and overgrowth on quartz by calcite (Figure 3E). The ground water supersaturated with silica also precipitated as overgrowth of quartz.

Apart from overgrowth of quartz, silica has been precipitated in the micro fractures of rock fragments. At some places micro grains of silica are present as overgrowth on carbonates. The precipitation of silica indicates that $\mathrm{pH}$ of solution was less than seven.

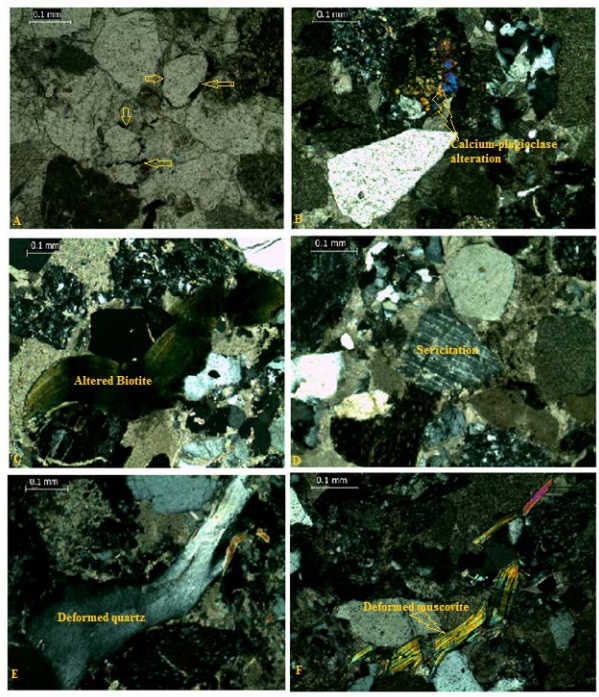


Figure 4: Photomicrographs showing (A) thin hematite cement coating around grains (PPL; 10X), (B) Plagioclase alteration (CN; 10X), (C) Biotite alteration into chlorite (CN; 10X), (D) Feldspar alteration into sericite (CN; 10X), (E) Deformation in strained quartz (CN; 10X), (F) highly deformed muscovite (CN; 10X).

\subsubsection{Hematite Cementation}

The red and black color of sediments has been observed in field and in thin sections. The sandstone of Nagri Formation is fractured and deformed due to tectonic uplift of the area. The sandstone is sometime coloured red due to the leaching and precipitation of hematite along fractures. The hematite also occurred as a thin coating around the grains (Figure 4A). The red staining on detrital quartz grains may represent iron oxides in the source area [7]. Other sources of iron may be chlorite and biotite observed in the thin sections. The biotite altered into chlorite (Figure 4C) releasing iron in the solution. In the oxidising condition, iron supersaturated solution will be reprecipitated as hematite and imparted red and brown color to the rock.

\subsubsection{Authigenic Clay Minerals}

Authigenesis of clay minerals took place during replacement of feldspar [4]. The replacement occurred along the cleavage and fractures. Feldspar grains are often partially to completely replaced by sericite (Figure 4D). The calcium plagioclase phenocrysts present in the volcanic basalt are altered (Figure 4B). Apart from feldspar replacement, biotite alteration into chlorite is also observed (Figure 4C). These solutions moved along the cleavage plains of the minerals and altered biotite into chlorite. The biotite replacement into chlorite might suggested deep burial diagenetic origin of chlorite.

\subsubsection{Late Diagenetic Deformation}

The bending of quartz (Figure 4E) and fractured mica (Figure 4F) are the epi-diagenetic processes representing tectonic uplifting of the area. The highly plastic deformation of mica is observed in the thin sections while in some thin sections bending of quartz and metamorphic rock fragments is also observed. The bending of quartz may indicate tectonic uplifting and plastic deformation of hydrolytically weak quartz grains. The plastic deformation of quartz can also be activated even at room temperature if the quartz is hydrolytically weakened and especially if the grain size has already been reduced by catalysis [8,9]. The tectonic processes of diagenesis have developed the secondary fractures in the rock. These fractures have enhanced the permeability and reservoir quality of the rock [10]. The fluids can also migrate upward through the inlets of these fractures.

\section{CONCLUSIONS}

The Nagri Formation sandstone of Miocene epoch in the Northern Mountaineous belt of Pakistan having some geological significances was studied. The data collected during outcrop study and petrographic analysis was interpreted. The outcome of research is described below.

- The calcite concretion in sandstone suggests warm, semiarid and arid climes for their genesis under hydromorphic condition. The hematite leaching along the petrified wood fossil favours continental origin of rock.
- Similarly, spheroidal weathering illustrates the combination of pressure relieving fractures and hydrolysis. The reaction of feldspar with silicate minerals during hydrolysis has formed clay minerals.

- The Drag folding and fractures in the beds of Nagri Formation are the evidence of deformation in the area.

- The fractures healed by quartz suggest that the mineral is precipitated by silica rich solution at low $\mathrm{Ph}$.

- The concavo-convex and sutured contacts between quartz, muscovite and rock fragment deformations, crumbling, fragmentation, mineral alterations and replacement along cleaved feldspar grains have declined the rock strength by promoting fracture propagations.

- The deformations in the rock were further assisted by tectonic upliftments of the area.

\section{REFERENCES}

[1] Ijaz, U., and Yasin, M. 2017. Determination of Ground water potential by electric resistivity method in Rawalakot and adjoining areas of the SubHimalayan fold and thrust Belt of Pakistan. Pakistan Journal of Geology, 1 (1), 01-04.

[2] Shah, S.M.I. 2009. Stratigraphy of Pakistan. Memoirs of the Geological Survey of Pakistan, 22, 293-298.

[3] Blatt, H., and Tracy, R. 1996. Petrology, Igneous, Sedimentary and Metamorphic. 2nd end., W. H. Freeman Pub. New York, 497.

[4] Yasin. M. 2017. Diagenesis of Miocene Sandstone in the District Sudunhoti and Poonch, Azad Jammu and Kashmir, Pakistan. Pakistan Journal of Geology, 1 (1), 05-07.

[5] Sorby, H. C. 1863. On the direct correlation of mechanical and chemical forces. Proceeding of the Royal Society of London, 12 (1862-1863), 583-550.

[6] Houseknecht, D.W. 1984. Influence of grain size and temperature on intergranular pressure solution, quartz cementation, and porosity in quartzes sandstone: Sediment. Journal of Sedimentary Petrology, 54 (2), 0348-0361.

[7] Yasin, M., Ali, S.M.K., Munir, M. H, and Ishfaque, M. 2017. The Sedimentary Geology, Remote sensing, Geomorphology and Petrology of Miocene to Late Pliocene sediments in District Sudhunhoti and Poonch, Azad Jammu and Kashmir, Pakistan. Earth Science Malaysia, 1 (1), 08-14.

[8] Gile, L.H., Peterson, F.F., and Grossman, R.B. 1965. The K horizon-a master soil horizon of carbonate accumulation. Soil Science, 99, 74-82.

[9] Kraus, M.J. 1999. Paleosols in clastic sedimentary rocks: their geological applications. Earth Science Reviews, 47, 41-70.

[10] Yasin, M., and Ibrahim, M. 2017. X-ray differaction analysis for the interpretation of clay minerals paragenesis in the neogene sediments of Mang and vicinity, Sub-Himalayas, Pakistan. Earth Science Malaysia, 1(1), 32-35. 